\title{
Statistical Predictions of Electric Load Profiles in the UK Domestic Buildings
}

\author{
A. M. Ihbal, H. S. Rajamani, R.A. Abd-Alhameed and M. K. Jalboub \\ School of engineering, Design and Technology University of Bradford, Bradford, BD7 1DP, UK \\ \{a.m.i.ihbal, h.s.rajamani , r.a.a.abd, m.k.jalboub\}@ Bradford.ac.uk
}

\begin{abstract}
This paper presents a method of generating realistic electricity load profile data for the UK domestic buildings. The domestic space features have been investigated excluding the heating and hot water systems. A questionnaire survey was conducted and the feedback were collected from a number of occupants at different intervals of times on daily bases in order to establish the probabilistic record of the estimated use of electrical appliances. The model concept of this study also considers the results of previous investigations such as that available in public reports and statistics as input data elements to predict the global domestic energy consumption. In addition, the daily load profile from individual dwelling to community can be predicted using this method. The result of the present method was compared to available published data and has shown reasonable agreement
\end{abstract}

Keywords: Energy, Energy Consumption, Electrical Appliances, Electrical Load Profiles

\section{INTRODUCTION}

The identification of the pattern of energy uses of a house and the prediction of domestic load profile is essential in order to match load shape to power generated. In the UK, the domestic energy-consumption can be divided into three categories: space heating, domestic hot water, lighting and appliance. The usage pattern varies depending on many determinants, such as weather, household composition, income, behaviour patterns of occupants; etc. Occupants influence the use of electricity of dwellings by the number of electrical appliances they own and throughout their use of the appliances.

The consumption per time interval is the sum of many consuming appliances. The load of a typical appliance connected to the grid is fluctuating over time and depending on time of usage. This results in a fluctuating electricity demand during a day and during a week. There are such many factors that influence the occupancy pattern such as:

- Number of people living in the house.

- The getting up time in the morning and the sleeping time.

- The unoccupied period during the day.
There have been numerous investigations dealing with domestic electricity consumptions and load profiles in the UK [1-8]. A monitoring campaign was undertaken by Newborough [1] where the energy demand data of 30 homes have been collected in order to modulate electricity demand emanating from individual dwellings to reduce the peak demand. A survey data among a sample of more than 1000 adults has been conducted and a questionnaire was designed in the south-east of England in order to collect information from consumers about environment, Ownership of appliances, Usage-patterns, and etc [2]. The result of this study, such as ownership level, and total energy consumption of certain appliances are generally used when modeling of domestic energy is carried out for the UK. A simple method of formulating load profile (SMLP) for UK domestic buildings was presented by R. Yao and K.A. Steemers [3]. The input data of the model was based mainly on public reports and statistics, such as the composition of households and average energy consumption of appliances per capita. The UK average size household ( 3 persons) was selected as an example of the implication of this method. A measurement of electrical energy consumption profiles for social sector in the UK, obtained over a period of 2 years was presented by Kreutzer [4]. The measurements were all obtained at 5 minute intervals. Annual energy consumptions, daily and overall profiles were derived for the dwellings from the data. An occupant survey was undertaken among the people living in the monitored dwellings in order to create a link between the energy consumption profiles and socio-economic factors. The monitored dwellings were categorised on the subject of floor area, number of occupants and ownership level of appliances. Paatero and Lund [5] presented a method for creating domestic electricity load profiles at individual household level. It is based on a bottom-up model where the household load composes individual appliances/appliance groups. The input data of the model was based mainly on public reports and statistics. Yigzaw, et al [6] studied The patterns of electricity consumption and how occupancy and housing characteristics affect domestic electricity use for 27 homes in various locations throughout Northern Ireland (city, town and village). The results of this study showed that there is a strong correlation between average annual electricity consumption 
and floor area. The Swedish Energy Agency recorded appliance consumption data of individual appliances for 400 households in order to understand where and how measures should be taken to increase the number of energy efficient appliances in the homes[7]. V.Hamidi and F. Li [8] presented a generalized tool to assess the responsiveness level among domestic consumers by studying load profiles for different domestic consumers which are composed of power consumption of end-use appliances and also showed the impact of different electricity tariffs on the load profile of domestic consumers. In this study, a method to generate load profiles for household electricity consumption is presented.

TABLE I

PERCENTAGE OF UK HOUSEHOLD SIZE [9]

\begin{tabular}{|c|c|}
\hline $\begin{array}{c}\text { No. of Persons in the } \\
\text { Household }\end{array}$ & Percentage \\
\hline 1 & $29 \%$ \\
\hline 2 & $35 \%$ \\
\hline 3 & $16 \%$ \\
\hline 4 & $13 \%$ \\
\hline 5 & $5 \%$ \\
\hline 6 or more & $2 \%$ \\
\hline Total & $100 \%$ \\
\hline
\end{tabular}

\section{METHODOLOGY}

The identification of the pattern of energy uses of a house and the prediction domestic load profile is essential in order to match load shape to the power generated, and also to predict the possible impact of any energy management action directly on the daily load profile. The produced electrical load profile is based on engineering assumptions as to the type of appliances owned and lighting that are in the house and when the occupants are likely to switch them on. The different households have different lifestyle, which mean the shape of total load profile will fluctuate from house to house and day to day. The inputs of electricity demand profile generator are:

- The Census Demographic results, which care available from the UK Office for National Statistics (ONS) [9].

- The annual electricity consumption such as ownership level of appliances, and total energy consumption of certain appliances [2].

Due to the lack of data about household occupancy pattern, it is necessary to make assumptions for the most common scenarios of household occupancy pattern in the UK as would be explained in section D. An Excel program has been developed in order to generate domestic load profile for different consumption

\section{A. Household composition}

The UK has a population of 61 million in 2008 and a total of 25 million households with an increase of almost 0.6 per cent on 2006. Since 1971 the population has increased by 5.0 million. The average household size is 2.4 . Table I and table II list the UK composition of households in 2008 and the type of households respectively [9].

TABLE II

TYPE OF HOUSEHOLD

\begin{tabular}{|c|c|}
\hline Type of Household & Percentage Share (\%) \\
\hline Single adult without children & 15 \\
\hline Single adult with children & 6 \\
\hline Single retired adult & 15 \\
\hline Two adults without children & 24 \\
\hline Two adults with children & 19 \\
\hline Two retired & 9 \\
\hline $\begin{array}{c}\text { Three adults or more without } \\
\text { children }\end{array}$ & 8 \\
\hline $\begin{array}{c}\text { Three adults or more with children } \\
\text { Total }\end{array}$ & 4 \\
\hline
\end{tabular}

\section{B. Domestic appliance Categories and Annual Electricity} Consumption

The information of the average daily consumption for major appliances in the UK household carried out by Mansouri [2]. The information gives the type and the average annual consumption per household per day, the average annual consumption per capita per day and the ownership level. Table III lists the average energy consumption of appliances in the UK. The ownership level for such appliances which have been marked by $(*)$ shown in table III are updated by Department for Environment, Food and Rural Affairs (defra) [10]. Fig 1 shows the Ownership level of domestic appliances in the UK. The daily energy consumption of electrical appliances for different types of household can be calculated based on Average annual consumption per day (per capita or per household).

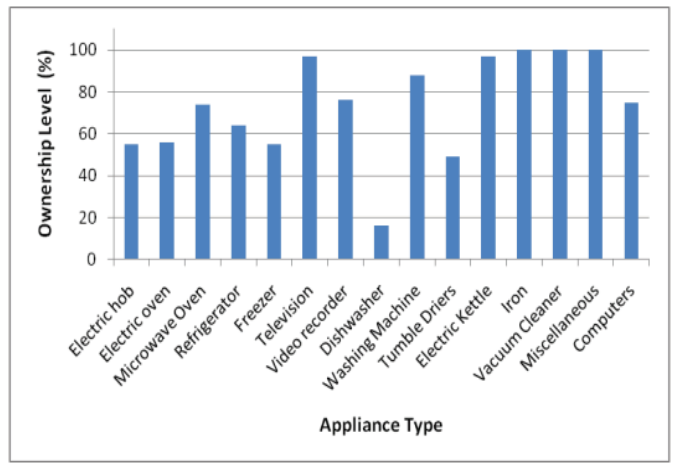

Figure1. Ownership level of domestic appliances 
Electrical Domestic appliances could be grouped into: brown goods, cold appliances, cooking appliances, wet appliances, and miscellaneous appliances. The domestic appliance categories in the UK are listed in table IV.

TABLE III

AVERAGE ENERGY CONSUMPTION OF ELECTRICAL APPLIANCES IN THE UK $[2,10]$

\begin{tabular}{|c|c|c|c|}
\hline Appliance & $\begin{array}{c}\text { Av. Annual Cons. } \\
\text { Per Household } \\
\text { (kwh/day) }\end{array}$ & $\begin{array}{c}\text { Av. Annual Cons. } \\
\text { Per Capita } \\
\text { (kwh/day) }\end{array}$ & Ownership level \\
\hline Electric hob & 1.33 & 0.39 & $55^{*}$ \\
\hline Electric oven & 0.74 & 0.22 & $64^{*}$ \\
\hline Microwave oven & 0.23 & 0.07 & 74 \\
\hline Refrigerator & 0.82 & 0.33 & 53 \\
\hline Freezer & 1.9 & 0.55 & 55 \\
\hline Fridge-freezer & 1.9 & 0.56 & 58 \\
\hline television & 0.91 & 0.27 & 97 \\
\hline Video recorder & 0.3 & 0.09 & 76 \\
\hline dishwasher & 1.72 & 0.48 & 16 \\
\hline W/Machine & 0.8 & 0.2 & 88 \\
\hline Tumble dryer & 0.78 & 0.28 & 49 \\
\hline Electric Kettle & 0.78 & 0.28 & $97^{*}$ \\
\hline Iron & 0.3 & 0.09 & 100 \\
\hline V. cleaner & 0.15 & 0.04 & 100 \\
\hline Miscellaneous & 1.1 & 0.33 & 100 \\
\hline Computers & 0.5 & 0.3 & 75 \\
\hline
\end{tabular}

TABLE IV

DOMESTIC APPLIANCES

\begin{tabular}{|l|l|}
\hline Brown goods & $\begin{array}{l}\text { Electric consumer goods : TVs, } \\
\text { VCRs, etc. }\end{array}$ \\
\hline Cold appliances & $\begin{array}{l}\text { Refrigerators, freezers, and } \\
\text { combined fridge-freezer. }\end{array}$ \\
\hline Cooking appliances & $\begin{array}{l}\text { electronic ovens, electric hobs, } \\
\text { kettles, and microwaves, etc. }\end{array}$ \\
\hline Wet appliances & $\begin{array}{l}\text { Washing machines tumble dryers, } \\
\text { and dishwashers. }\end{array}$ \\
\hline $\begin{array}{l}\text { Miscellaneous } \\
\text { appliances }\end{array}$ & $\begin{array}{l}\text { Vacuum cleaners, irons, electric } \\
\text { showers, PCs, etc. }\end{array}$ \\
\hline Lighting & Lights \\
\hline
\end{tabular}

The following assumptions have been made in order to generate appliances load profile:

- $\quad$ Each household has only one of each appliances listed above.

- The space heating and hot water systems are excluded from this study.
- The weekend hourly load curves have been equalized to those for the workdays for calculation simplicity.

- The space heating and hot water systems are provided by means of natural gas. Although the boiler uses electric powered burner, the electric consumption of this burner is too small and has not been considered

\section{Electric lighting patterns}

The electric light depends on the occupancy pattern and is highly affected by daylight condition (season) and the presence of active occupants, e.g.in winter, people need to switch on the artificial Lighting in the morning for the activities but in summer due to the daylight no artificial lighting required.The following equation can be used to calculate the electric lighting energy consumption $\left(E_{l}\right)$ :

$$
E_{l}=N_{b} \times E_{r b}
$$

Where, $\mathrm{N}_{\mathrm{b}}$ is the number of light bulbs per household distributed between bedrooms, kitchen, living room, bathrooms and others and is the energy rating per bulb per hour.

\section{Occupancy scenarios}

The usage of electrical appliances is associated to the occupancy period. The total energy load profile can vary significantly from time to time depending on number of occupants, their behaviours and the unoccupied period during the day. For example, when there is nobody at home; most appliances will not be in use. In daily appliance electricity profile, the occupants consume practically low power during the night (e.g. cold appliances), getting up, having breakfast and leaving the house during the morning and then may come again around lunch time, in the evening, many activities are done: cooking the meal, taking a shower and watching television, etc.

Due to the lack of data about household occupancy pattern, it is necessary to make assumptions for the most common scenarios of household occupancy pattern in the UK. Eight scenarios of occupancy pattern have been assumed according to household type.

Scenario 1: single working adult household, the occupier is a full time working and the unoccupied period is from 08:30 to 18:00.

Scenario 2: Single retired adult, the house is occupied all the time.

Scenario 3: Single adult with children household, the occupier is a part time working and the unoccupied period is from 08:30 to $14: 00$.

Scenario 4: Two adults, both occupants have a full time job. The unoccupied period is from 08.30 to 18.00 .

Scenario 5: Two adults with children, one occupant has a full time job and the other adult may have a part time job in the 
morning in order to take care of the children after school. The unoccupied period is from 08.30 to 13.00 .

Scenario 6: Two retired, the house is occupied all the time. Scenario 7: Three adults or more, two members may have a full time job; the other one may have a part time job in the afternoon session. The unoccupied period is from 13:00 to 18:00

Scenario 8: Three adult household with children. The house is occupied all the time, two occupants have a full time job and the other one is retired.

\section{GENERATING A TYPICAL LOAD PROFILE}

To perform a typical load profiles for UK households using the eight scenarios, the daily electricity consumption load profiles of electric appliances have been calculated for a winter and summer seasons

The daily energy consumed by each appliance can be calculated using one of the following equations:

$$
\begin{aligned}
& E_{a}=N \times \sum E_{a p c} \\
& E_{a}=\sum E_{a p h}
\end{aligned}
$$

Where $E_{a}$ is the daily energy consumption of household delivered by appliances; $\mathrm{N}$ is the number of occupants, $E_{\text {apc }}$ is the appliance energy consumption per capita and $E_{a p h}$ is the appliance energy consumption per household.

\section{A. Allocation of Households}

Due to lack of data and in order to allocate a number of different households, a community of 400 different household types based on the national UK household percentage share has been assumed. Then the number of households for each household type has been allocated randomly using excel's rand function. Fig 2 shows the projected number of households of the assumed community.

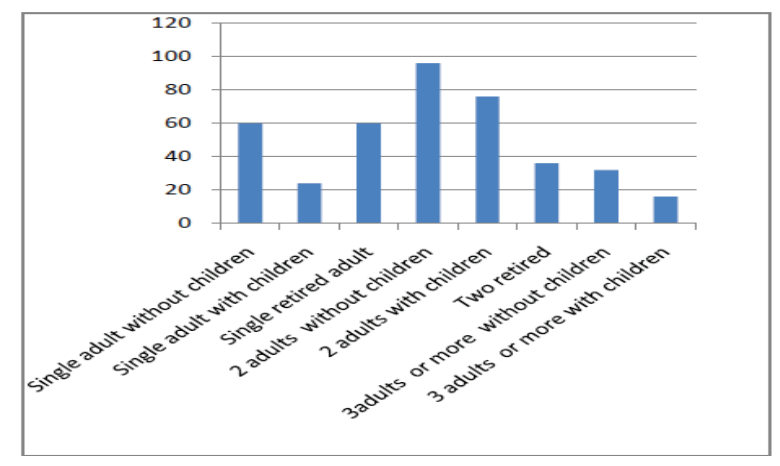

\section{B. Time of Use Probability Profiles}

In order to create sensible load profiles, knowledge of occupancy patterns is required. The occupancy information was limited, so simpler assumptions have been made for each scenario. Although the demand for cold appliances normally varies during the duty cycle of the appliance, the assumption of constant load is assumed to be sufficiently accurate [11], the remaining appliances will have discrete events where the appliance is switched on and utilised. The usage time and probability of occurrence of each appliance was distributed randomly based on the occupancy period. The time of use probability is determined based on the questionnaire survey as shown in figure 3 . The lighting load was dealt separately.

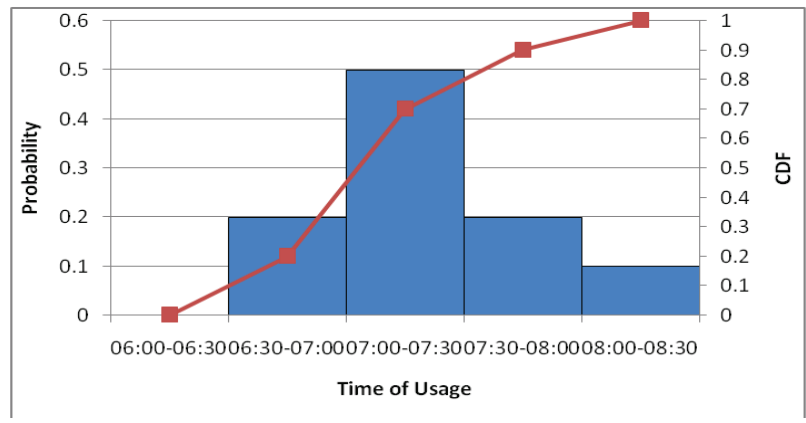

Figure 3. Probability of first usage times per day for the hob for the single adult household.

\section{Electricity Demand Profile Generator}

The random profile generator is an Excel program that aims to simulate the random action of the household at half hourly basis in order to generate electrical load profiles that match the consumption target. It is based on probability that enable us to predict the possibility of each consumer to operate a number of appliances on a certain time of the day for different occupancy scenarios by describing the behaviour of each appliance by a probability between $(0 \& 1)$. A random profile of each individual appliance for each scenario will be generated using Random Number Generator technique (RNG). The aggregation of the whole random profiles for all appliances will generate a daily consumption load profile for a known scenario. Fig 4 shows the framework of generating a typical single household load profiles.

The load profile for the whole community was calculated using the equation:

$$
\operatorname{Load}_{\text {community }}=\sum_{j=1}^{8} E_{a j}
$$

Where; Load community is the load profile for the whole community; $E_{a j}$ is the half hourly load profile of household of type $\mathrm{j}$.

Figure 2. Projected numbers of households 


\section{RESULTS OF MODELED DATA}

A typical load profiles for UK households for different common scenarios have been generated using the mentioned method. The daily energy consumption load profiles of electric appliances and lighting loads have been generated individually for a winter and a summer seasons. The total daily electricity demand profile for the community is generated by aggregating the load profiles of the eight scenarios.

The average half hourly daily energy consumption of a single household for each household type (scenario) is obtained by dividing the total electricity consumption for the entire number of households for each scenario at a specific time by the total number of households for the same scenario at the same time as shown in Fig 4.

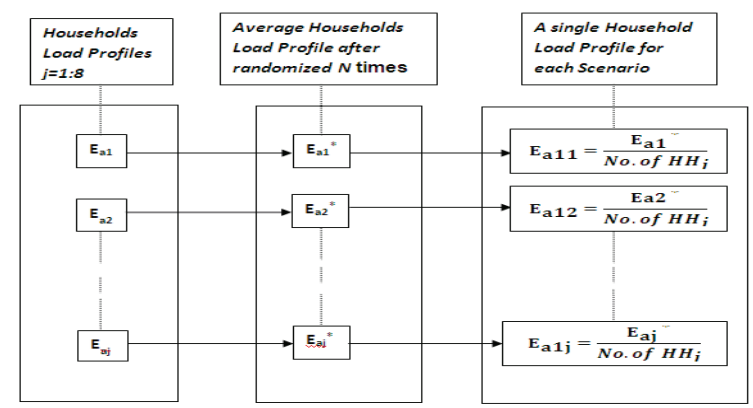

Figure 4. Framework of producing a typical single household load profile
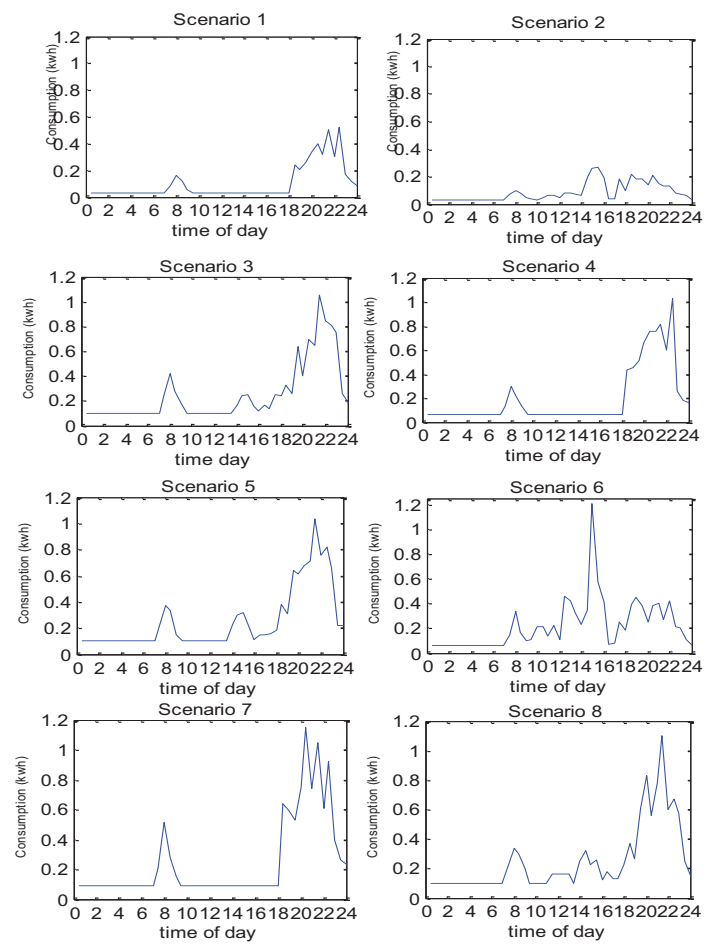

Figure 5. Average half-hourly daily consumption for the whole scenarios
The average load profile for a single household for the whole community (eight scenarios together) is calculated by averaging the summation of the averages of all scenarios. The modeling results for the whole scenarios are shown in Fig 5.

Share of Electricity consumption by household domestic appliances is shown in figure 6 . Wet appliances accounted for 20 percent of the total amount of electricity consumed for while miscellaneous accounted for 19 percent, cold appliances accounted for 18 percent and the lighting presents 13 percent.

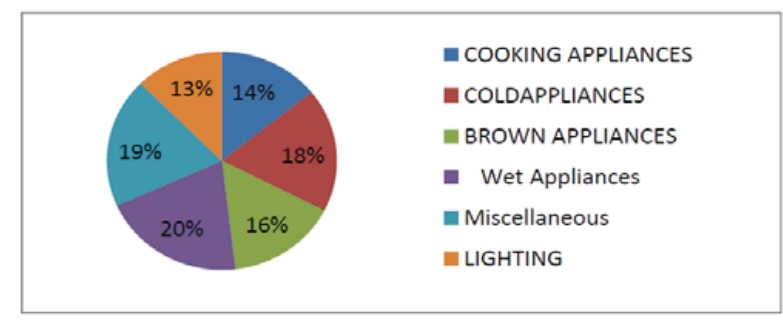

Figure 6.Electricity consumption by appliance type

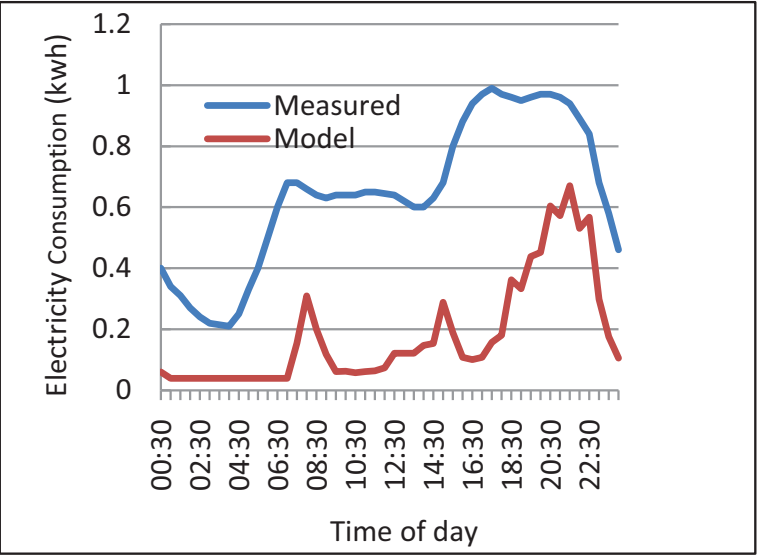

Figure 7. Comparison of modelled load profile with measured data

\section{COMPARISION OF GENERATED PROFILES WITH MEASURED DATA}

During the period between December 2003 and February 2004, Yigazw G. Yohanis and others performed electricity measurement using a half-hour load meter for 27 dwelling in Northern Ireland to obtain an understanding of how occupancy and dwelling characteristics affect domestic electricity use [6]. When compared the average daily consumption for a single household for the eights scenarios (Fig.5) with the average daily annual electricity consumption measured by Yigazw [6], we can note that, there is a good agreement between the both curves and the general patterns are still clearly captured by the model, for example, the minimum consumption is occurring between 1.00 and 6.00 am (unoccupied periods), for the latter the consumption is 
almost has the same pattern from about 9.00 a.m. to midnight. The maximum consumption is occurring between 18.00 and 22.00. The average daily electricity consumption from the produced model data in the winter season is about 9 $\mathrm{KWh}$, and about $13 \mathrm{KWh}$ from a national load profile [3]. The profile from modeled data is slightly lower than the national profile as shown in Fig 7; because it is related only to the domestic appliance and does not include the space heating and hot water systems load (the assumption is that they are provided by means of natural gas).

\section{CONCLUSIONS}

In this paper a method of generating realistic electricity load profile data for the UK domestic buildings has been presented. This method is based on the information and results of previous investigations and works that is available in public reports and statistics.

Eight scenarios which present the behavioural characteristics and common occupancy pattern in the UK households have been proposed to predict the diversity in electricity consumption between households. A half hourly daily load profiles for assumed community of 400 households have been generated for eight scenarios and then the average electricity consumption for individual house which presents the whole community has been plotted. The generated load profile has shown a reasonable agreement compared with the typical national load profile.

This method has allowed the creation of typical seasonal and lifestyle activity profiles from statistical data and could be useful for predicting the future electricity demand from individual house to whole community. The analysis shows the power requirements of each electrical appliance and helps to determine the suitability of applying renewable energy and adopting demand response in the domestic sector.

\section{REFERENCES}

[1] M. Newborough, P. Augood, "Demand-side management opportunities for the UK domestic sector," IEE proceedings generation transmission distribution, 1999, 283-293.

[2] I. Mansouri, M. Newborough, D. Probert, "Energy Consumption in the UK Households: Impact of Domestic Electrical Appliances, ” Applied Energy 54 (3) (1996) 211-285.

[3] I R. Yao, K.A. Steemers, "A method of formulating energy load profiles for domestic buildings in the UK," Energy and Buildings 37 (2005) 663-671.

[4] N. Kreutzer" I. Knight, "Social housing electrical energy consumption profiles in the United Kingdom, "2nd International Solar Cities Congress, Oxford, April 2006.

[5] J.V. Paatero, P.D. Lund, "A model for generating household electricity load profiles", International Journal of Energy Research 30 (5) (2006) 273-290.

[6] Yigzaw G.Yohanis, Jayanta D. Mondol, Alan Wright, and Brian Norton, Real-life energy use in the UK: How occupancy and dwelling characteristics affect domestic electricity use, Energy and Buildings 40 (2008) 1053-1059.

[7] P. Bennich and A. Persson, "Proceedings of the Methodology and First Results from End-Use Metering in 400 Swedish Households," Energy Efficiency in Domestic Appliances and Lighting (EEDAL) conference London (June 2006).

[8] V.Hamidi, F. Li "Demand Response in the UK's Domestic Sector," Electric Power Systems Research, 79(2009) 1722-1726.
[9] Social trends, No. 39-2009 edition, Office of National Statistics[Online].Available:http://www.statistics.gov.uk/downloads/the me social/Social Trends39/Social Trends 39.pdf.

[10] Annex 12: Domestic Cooking Appliances.[Online]. Available: http://www.defra.gov.uk/corporate/consult/energy-usingproducts/annex12.pdf

[11] Widén J, Lundh M, Vassileva I, Dahlquist E, Ellegård K, Wäckelgård E. Constructing load profiles for household electricity and hot water from timeuse data-modelling approach and validation. Energy Build 2009;41:753-68. 